\title{
Comparison of the epidemiology, profile of mutations, and clinical response to antiretrovirals among subtypes $B$ and $F$ of the human immunodeficiency virus type 1
}

\author{
Heloisa Ramos Lacerda/*/**/+, Luzidalva Barbosa de Medeiros**, \\ Ana Maria Salustiano Cavalcanti***, Ricardo Arraes de Alencar Ximenes*, \\ Maria de Fátima Pessoa Militão de Albuquerque/*/**
}

\begin{abstract}
Hospital das Clínicas *Pós-Graduação em Medicina Tropical **Departamento de Medicina Clínica, Universidade Federal de Pernambuco, Av. Moraes Rego, s/nº, Cidade Universitária, 50670-420 Recife, PE, Brasil ***Laboratório Central, Secretaria Estadual de Saúde de Pernambuco, Recife, PE, Brasil
\end{abstract}

The authors compared demographic aspects and profile of mutations in 80 patients with subtypes $B$ and $F$ of human immunodeficiency type 1 (HIV-1). Genotyping of the pol region of the reverse transcriptase was performed using the ViroSeqTM Genotyping System. A total of 61 (76.2\%) patients had subtype B and 19 (23.8\%) subtype $F$ of the HIV-1. Subtype F tended to be more frequent in heterosexuals and women with a low educational level, but without statistical significance. The frequency of mutations related to nucleoside reverse transcriptase inhibitors and protease inhibitors (PI) was the same in the two subtypes, but mutations related to PI at the codons 63, 77, and 71 were more frequent in subtype $B$, while mutations at the codons 36 and 20 predominated in subtype F. Sixty-two of the 80 patients infected with subtypes $B$ and $F$ were submitted to antiretroviral therapy for an average of 18-22 months. Undetectable viral loads at the end of follow-up were similar in the two groups, representing $63.8 \%$ of subtype $B$ and $73.3 \%$ of subtype $F(p=0.715)$. CD4 lymphocyte counts before and after treatment were similar in the two groups. This study, despite pointing to possible epidemiological and genetic differences among subtypes B and F of HIV-1, suggests that the use of highly active antiretroviral therapy is equally effective against these subtypes.

Key words: human immunodeficiency virus type 1 - subtypes - genotyping - antiretroviral therapy

Human immunodeficiency virus type 1 (HIV-1) subtypes $\mathrm{B}$ and $\mathrm{F}$ are the most prevalent in South American countries (Masciotra et al. 2000, Avilla et al. 2002, Brindeiro et al. 2003, Montano et al. 2005, Rios et al. 2005, Geretti 2006). Brazil has the largest population and the majority of cases of HIV/AIDS (a total of 433,067 cases) in the region (Brazilian Ministry of Health 2006) and subtype B is the most predominant (Brindeiro et al. 2003). However, probably due to its huge size and large population, HIV epidemics vary in nature and complexity. In the Northeast (where the state of Pernambuco is located), the North, the Center-west, and the Southeast Regions of Brazil, the prevalence of subtype B ranges from 70 to $96 \%$. Subtype F occurs in 4.9 to $12 \%$ of the patients and the prevalence of the recombinant forms, mainly $\mathrm{B} / \mathrm{F}$, ranges from 0.2 to $14.4 \%$ (Brindeiro et al. 2003, Cerqueira et al. 2004, CoutoFernandes et al. 2005, Rodrigues et al. 2005, Barreto et al. 2006). In these regions the presence of subtype $C$ is insignificant. However, in the South Region the profile

Financial support: National Program of STD/AIDS, Brazilian Ministry of Health

+Corresponding author: helramos@terra.com.br

Received 8 January 2007

Accepted 1 August 2007 of subtypes is different: there is an increasing frequency of subtype C, detected after 1990, which ranges from 29.8 to $44.9 \%$ and a high prevalence of mosaics (22\%) (Brindeiro et al. 2003, Soares et al. 2003). In the state of Rio Grande do Sul (in the South Region), the frequency of subtype C (44.9\%) is now higher than that of subtype B, which occurred in just $29.9 \%$ of HIV cases (Brindeiro et al. 2003).

There are several unresolved questions regarding the differences between subtypes B and F of HIV-1: whether they differ regarding pathogenicity, biological properties, epidemiological features, transmissibility, and mutations related to antiretroviral resistance (Essex et al. 1997, Thompson et al. 2002, Apetrei et al. 2004, Pires et al. 2004, Kantor et al. 2005, Pinto \& Struchiner 2006). Most importantly, there are doubts as to whether the efficacy of antiretroviral agents is similar for the B and non-B subtypes (Acceturi et al. 2000, Frater 2002, Atlas et al. 2005, Bocket et al. 2005, Geretti 2006), given the lack of data due to the restricted access to antiretrovirals (ARV) in different parts of the world where non-B subtypes are more prevalent. The answer to this question will certainly have major clinical implications for therapeutic strategies in South American countries.

We therefore conducted this study in order to assess the prevalence of subtypes of HIV-1 and to evaluate differences in the epidemiology, profile of mutations, and clinical response to antiretrovirals among patients infected with subtypes $\mathrm{B}$ and $\mathrm{F}$ in attendance at a reference center for HIV/AIDS treatment in the state of Pernambuco. 


\section{PATIENTS AND METHODS}

Study population - A total of 84 drug-naïve individuals infected by HIV-1 consecutively seen at their first medical consultation at the Federal University of Pernambuco Hospital in Recife, Brazil, in the year 2002 were invited to participate in the study. Those who agreed to participate signed a consent form, answered a questionnaire, and were submitted to the genotyping assay. Those patients who fulfilled the criteria of indication for antiretroviral treatment based on the 2002 Consensus in Antiretroviral Therapy for Adults of the Health Ministry (Brazilian Ministry of Health 2002) i.e. CD4 lymphocyte count below 350 cells $/ \mathrm{mm}^{3}$, symptoms or opportunistic diseases related to AIDS, were given antiretroviral treatment funded by the Brazilian government. All patients received highly active antiretroviral therapy (HAART) (containing at least three antiretrovirals): the schemas contained 2 nucleoside reverse transcriptase inhibitors (NRTI) +1 non-nucleoside transcriptase inhibitor (NNRTI) or 2 NRTI +1 protease inhibitor (PI). The selection of the antiretroviral was aleatory and determined in consultation with his or her clinician, who did not know the patient's viral subtype. The patients were followed up prospectively and submitted to CD4 lymphocyte counts (measured by flow cytometry) and viral load measurements (measured by the nucleic acid based amplification assay) every 4-6 months. All the 80 patients with subtypes B and F of the HIV-1 were included in the analysis of the demographic aspects and profile of mutations; however, for the analysis of the therapeutic response, those that did not begin antiretroviral treatment, those who were followed up for less than 6 months, and those who abandoned the treatment were excluded, leaving a total of 62 individuals (Figure).

Outcome - The maintenance of an undetectable viral load at the end of the period of observation was considered a favorable outcome and an unfavorable outcome was defined as a viral load greater than 400 copies $/ \mathrm{ml}$, (i.e. above the level of detection) at the end of the follow-up or the occurrence of death during the treatment.

Drug resistance genotyping - The ViroSeq ${ }^{\mathrm{TM}} \mathrm{HIV}-1$ Genotyping System (Celera Diagnostic, Abbott Laboratories, US) was used to identify the resistance-associated mutations in the HIV-1 polymerase (pol) gene. The process comprises the isolation and purification of plasma viral RNAs by ultra centrifugation $(21,000 \mathrm{~g} \mathrm{x}$ for $120 \mathrm{mn}$-sample preparation module), followed by cDNA synthesis and genomic amplification by polymerase chain reaction assay (PCR) of the HIV-1 pol fragment (reverse transcriptase RT-PCR and PCR module), spanning the entire protease (PR) gene and approximately two thirds of the RT gene. A $1.8 \mathrm{~Kb}$ amplicon fragment was subsequently used as a sequencing template to generate approximately $1.2 \mathrm{~Kb}$ of HIV-1 sequence data.

The amplified PCR products were sequenced using seven primers included in the kit, formulated with the BigDye Terminator sequencing chemistry (Sequencing Module-Big Dye v.2.0). The sequencing products were analyzed on an ABI Prism ABI 3100 Genetic Analyzer (Applied Biosystems, US) coupled to the DNA sequencing analysis software.

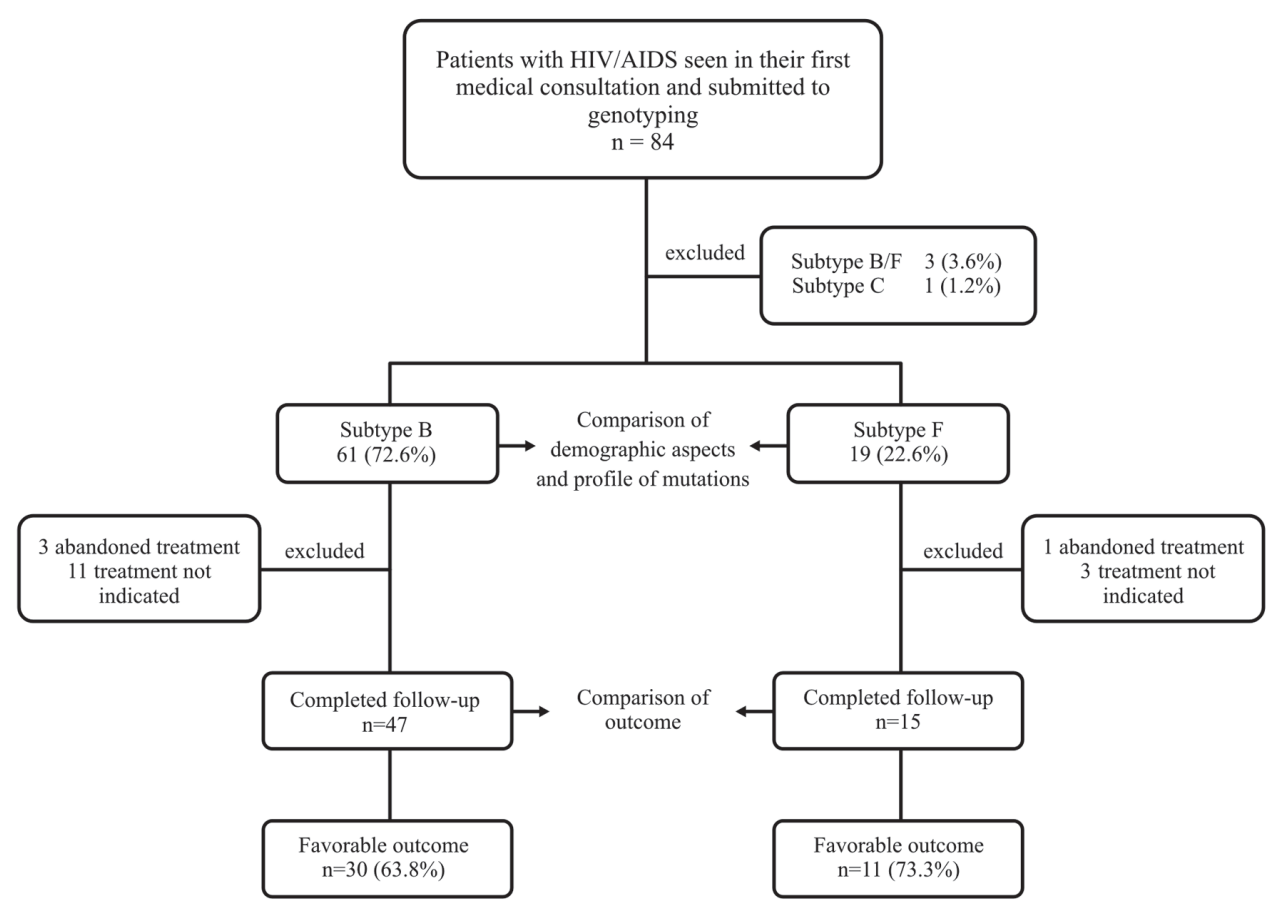

Flow chart of the patients with human immunodeficiency virus or acquired immunodeficiency syndrome submitted to genotyping assay and treatment. 
The ViroSeq ${ }^{\mathrm{TM}} \mathrm{HIV}-1$ Genotyping System consists of a software that automatically imports the sequence data from the sequence analysis software and assembles seven or six sequences segments into a single sequence, which is then compared to the HXB2 reference strain (Kuiken et al 2003). After the edition and establishment of the consensus sequence, the mutation analyses software (ViroSeqTM software v.2.6) generates the resistance mutation profiles for the different ARV drugs.

HIV-1 subtyping - For the determination of the genetic subtypes of the HIV-1 all sequences were analyzed using the Stanford Sequence Resistance Database (http:/ /hivdb.stanford.edu). Mutation resistance profiles were classified according to the International AIDS Society consensus (D'Aquilla et al. 2002).

Ethics - The study was approved by the Ethics Commission of the University's Health Sciences Center (Protocol Number 158/2001-CEP/CCS).
Statistical analysis - Differences in proportions of social and biological features, viral load, frequency of mutations and outcome of patients with subtypes B and F were evaluated using the chi square test, Yates corrected chi square, and the Fisher Exact test for expected sizes of five or less. The Student's t-test was used to compare the means of CD4 and the duration of followup. Statistical analysis was performed using EPI-INFO.

\section{RESULTS}

A total of 84 patients were evaluated, of whom 61 (72.6\%) were infected with HIV-1 subtype B, 19 (22.6\%) subtype F, $3(3.6 \%)$ subtypes B/F, and $1(1.2 \%)$ with subtype C. The 80 patients that were infected with subtypes B and F of HIV-1 were analyzed for demographic characteristics, frequency, and profile of mutations. Females accounted for $52.6 \%$ of the patients with subtype F, while only $31.1 \%$ of the subtype B patients were females, although the difference was not statistically sig-

TABLE I

Demographic, biological, risk behavior, and profile of mutations of 80 patients infected with the subtypes B and F of human immunodeficiency virus type 1

\begin{tabular}{|c|c|c|c|c|c|}
\hline & & & & & \\
\hline & $\mathrm{N}$ & $\%$ & $\mathrm{~N}$ & $\%$ & p-value \\
\hline Sex & & & & & \\
\hline Male & 42 & 69.8 & 9 & 47.4 & $0.153^{a}$ \\
\hline Female & 19 & 31.1 & 10 & 52.6 & \\
\hline Schooling & & & & & \\
\hline Less than 8 years schooling & 36 & 59 & 16 & 84.2 & $0.082^{b}$ \\
\hline More than 8 years schooling & 25 & 41 & 3 & 15.8 & \\
\hline Sexual risk behavior & & & & & \\
\hline Heterosexual & 34 & 55.7 & 15 & 78.9 & $0.122^{a}$ \\
\hline Men who have sex with men & 27 & 44.3 & 4 & 11.1 & \\
\hline IV drug use & & & & & \\
\hline Yes & 2 & 3.3 & 0 & 0 & $0.996^{a}$ \\
\hline No & 59 & 96.7 & 19 & 100 & \\
\hline Mutations & & & & & \\
\hline $\begin{array}{l}\text { Patients with mutations related to } \\
\text { nucleoside reverse transcriptase }\end{array}$ & & & & & \\
\hline inhibitors $^{c}$ & 4 & 6.5 & 4 & 21 & $0.161^{a}$ \\
\hline M41L & 1 & 1.6 & 1 & 5.3 & - \\
\hline $\mathrm{K} 219 \mathrm{E}$ & 3 & 4.9 & 1 & 5.3 & - \\
\hline E44D & - & - & 1 & 5.3 & - \\
\hline V118I & - & - & 1 & 5.3 & - \\
\hline Patients with mutations related to & & & & & \\
\hline protease inhibitors ${ }^{c}$ & 45 & 73.8 & 18 & 94.7 & $0.103^{b}$ \\
\hline L63P & 36 & 59 & 3 & 15.8 & $0.000^{a}$ \\
\hline V77I & 12 & 19.7 & - & - & - \\
\hline $\mathrm{A} 71 \mathrm{~V} / \mathrm{T}$ & 8 & 13.1 & - & - & - \\
\hline M36I & 8 & 13.1 & 18 & 94.7 & $0.000^{a}$ \\
\hline $\mathrm{L} 10 \mathrm{I} / \mathrm{V}$ & 7 & 11.5 & 9 & 31.6 & $0.085^{a}$ \\
\hline K20R & 1 & 1.6 & 8 & 42.1 & $0.000^{b}$ \\
\hline I54P & 1 & 1.6 & - & - & - \\
\hline Total of patients & 61 & 100 & 19 & 100 & \\
\hline
\end{tabular}

$a: \chi^{2}$ for percentage; $b: \chi^{2}$ Yates corrected; $c$ : sequences containing more than one mutation related to the same class of antiretroviral was scored as one. 
nificant $(\mathrm{p}=0.153)$. The most frequent means of transmission was sexual, particularly heterosexual practice. Seventy nine $(78.9 \%)$ of the patients with subtype F were infected by heterosexual transmission, against $55.7 \%$ of the subtype B patients, but again this difference was not significant $(\mathrm{p}=0.122)$. Patients infected with subtype $\mathrm{F}$ tended to have less schooling than patients with subtype $\mathrm{B}(\mathrm{p}=0.082)$ (Table I).

Mutations related to NRTI and to PI were more frequent in the patients infected with subtype F, albeit without statistical significance $(\mathrm{p}=0.161$ and 0.103 respectively). The frequency of mutations in each subtype is shown in Table I.

Of the 80 patients with subtypes B and F, 62 were evaluated regarding their response to treatment, 47 of whom infected with subtype B and 15 with subtype F. Of the remaining 18, 14 did not have an indication for antiviral therapy and 4 abandoned the treatment, being therefore excluded from the analysis of outcome (Figure). Table II summarizes the virologic and immunologic features of the patients before starting antiretroviral treatment and at the end of follow-up. Before starting treatment most patients in both groups presented a viral load above 100,000 copies $/ \mathrm{ml}$; the patients infected with subtype B had a mean CD4 lymphocyte count of 131.5 cells $/ \mathrm{mm}^{3}$ and those infected with subtype $\mathrm{F}$, one of 164.8 cells $/ \mathrm{mm}^{3}$. At the end of follow-up there was a similar increase in CD4 lymphocytes in the two groups, and the frequency with which they achieved an undetectable viral load was also similar. The duration of followup was 20.2 months in subtype B and 22.8 months in subtype $\mathrm{F}$. The proportion of patients using regimens of HAART containing NNRTI or with PI was similar in the two groups.

A favorable outcome, in other words, an undetectable viral load (< 400 copies/ml) occurred in $30(63.8 \%)$ patients with subtype B and in $11(73.3 \%)$ patients with subtype F, with no significant differences between the groups. Five $(10.6 \%)$ patients died in the subtype B group and none in the group of patients with the subtype F of HIV-1 during the study (Table II).

Association of outcome with biological and virological characteristics (including subtype B or F of the HIV1) and the treatment used did not show any significant differences between those with a favorable outcome and those with an unfavorable one, although the use of 2

TABLE II

Virological and immunological features of 62 patients with subtypes B and F of human immunodeficiency virus that completed treatment

\begin{tabular}{|c|c|c|c|c|c|c|c|}
\hline \multirow{3}{*}{$\begin{array}{l}\text { Virological and } \\
\text { immunological features }\end{array}$} & \multicolumn{4}{|c|}{ Subtypes } & \multirow{2}{*}{\multicolumn{2}{|c|}{ Total }} & \multirow[b]{3}{*}{$\mathrm{p}$-value } \\
\hline & \multicolumn{2}{|c|}{$\mathrm{B}$} & \multicolumn{2}{|c|}{$\mathrm{F}$} & & & \\
\hline & $\mathrm{N}$ & $\%$ & $\mathrm{~N}$ & $\%$ & $\mathrm{~N}$ & $\%$ & \\
\hline \multicolumn{8}{|l|}{ Pre-treatment viral load ${ }^{a}$} \\
\hline$<100,000$ copies $/ \mathrm{ml}$ & 11 & 29 & 5 & 45.5 & 16 & 22.4 & $0.507^{c}$ \\
\hline$\geq 100,000$ copies $/ \mathrm{ml}$ & 27 & 71 & 6 & 54.5 & 33 & 77.6 & \\
\hline Total & 38 & 100 & 11 & 100 & 49 & 100 & - \\
\hline \multicolumn{8}{|l|}{ End of treatment viral load $b$} \\
\hline Undetectable & 30 & 71.4 & 11 & 73.4 & 41 & 72 & $0.759^{c}$ \\
\hline Detectable & 12 & 28.6 & 4 & 26.6 & 16 & 28 & \\
\hline Total & 42 & 100 & 15 & 100 & 57 & 100 & - \\
\hline Number of CD4 (cells $\left./ \mathrm{mm}^{3}\right)$ & \multicolumn{2}{|c|}{ Mean \pm SD } & \multicolumn{2}{|c|}{ Mean \pm SD } & \multicolumn{2}{|c|}{ Mean \pm SD } & \\
\hline Basal CD4 & \multicolumn{2}{|c|}{$131.5 \pm 105.2$} & \multicolumn{2}{|c|}{$164.8 \pm 130.9$} & \multicolumn{2}{|c|}{$139.7 \pm 111.7$} & $0.354^{d}$ \\
\hline Final CD4 & \multicolumn{2}{|c|}{$422.9 \pm 238.7$} & \multicolumn{2}{|c|}{$464.8 \pm 131.6$} & \multicolumn{2}{|c|}{$433.7 \pm 215.8$} & $0.536^{d}$ \\
\hline \multicolumn{8}{|l|}{ Scheme of treatment } \\
\hline 2NRTI + NNRTI & 29 & 61.7 & 11 & 73.3 & 40 & 64.5 & $0.610^{c}$ \\
\hline $2 \mathrm{NRTI}+\mathrm{PI}$ & 18 & 38.3 & 4 & 26.7 & 22 & 35.5 & \\
\hline \multicolumn{8}{|l|}{ Outcome } \\
\hline Unfavorable & 17 & 36.2 & 4 & 100 & 21 & 33.8 & $0.715^{c}$ \\
\hline Viral load $>400$ copies $/ \mathrm{ml}$ & 12 & 70.6 & 4 & 100 & 16 & 76.2 & \\
\hline Death & 5 & 29.4 & 0 & 0 & 5 & 23.8 & \\
\hline \multicolumn{8}{|l|}{ Favorable } \\
\hline Viral load < 400 copies $/ \mathrm{ml}$ & 30 & 63.8 & 11 & 73.3 & 41 & 66.2 & \\
\hline $\begin{array}{l}\text { Duration of treatment } \\
\text { (months) }\end{array}$ & $20.2 \pm 10.2$ & & $22.8 \pm$ & & $20.8 \pm 9.8$ & & $0.370^{d}$ \\
\hline Total & 47 & 100 & 15 & 100 & 62 & 100 & \\
\hline
\end{tabular}

$\bar{a}$ : subtype $\mathrm{B}$, information missing in 9 patients; subtype $\mathrm{F}$, information missing in four patients; $b$ : subtype $\mathrm{B}$, information missing in five patients; $c$ : chi-square test; $d$ : t-student test. 
NRTI+PI produced an unfavorable outcome in half the patients against $26.1 \%$ of unfavorable outcomes in those using 2 NRTI+NNRTI, but this did not attain statistical significance (Table III).

\section{DISCUSSION}

Subtypes B and F of HIV-1 accounted for $95.2 \%$ of the samples, a similar distribution to the other countries in the region (Avilla et al. 2002, Brindeiro et al. 2003, Montano et al. 2005, Rios et al. 2005). A limitation of this study was the methodology used for the sequence analysis of viral diversity, which would be better done using a bootscanning program, such as the Simplot program. However, if it is assumed that the frequency of recombinant forms $\mathrm{B} / \mathrm{F}$ or mosaics has been underestimated in the study, it is likely that the same proportion of them will have been missed in the two groups, which will not have compromised the results.

While not achieving statistical significance, some aspects already described in South America seem to occur in the population of the present study: a higher frequency of subtype F among women, in the heterosexual population and those with less schooling, as compared with the greater prevalence of subtype B in men-whohave-sex-with-men and those with more schooling (Masciotra et al. 2000, Avilla et al. 2002, Montano et al. 2005, Rios et al. 2005). In our study the difference was not so apparent, but certainly a large number of patients will show the same tendency. Some have argued that subtype F spreads more easily through heterosexual transmission (Masciotra et al. 2000, Avilla et al. 2002, Montano et al. 2005, Rios et al. 2005), using the argument that the susceptibility of Lagerhans' cells to infection by subtype B seems to be substantially lower when compared with the non-B subtypes (for example A, C, and E subtypes) (Soto-Ramirez et al. 1996, Essex et al. 1997). However it has recently been proved that Langerhans' cells are just as susceptible to subtype B as other non-B subtypes of HIV-1 (Solis et al. 2006). A recent phylogenetic study of subtypes B and F in Brazil offers another possible explanation for this difference: it could possibly result from the restricted circulation of subtypes among groups with similar risk behavior, but with little contact between the groups in question (Bello et al. 2006). The authors suggested that each subtype epidemic was the result of the original introduction, at dif-

TABLE III

Relation of outcomes of the antiretroviral treatment and the social, biological, virological, and immunological features of 62 patients

\begin{tabular}{|c|c|c|c|c|c|c|}
\hline \multirow{3}{*}{$\begin{array}{l}\text { Socio-demographic } \\
\text { features }\end{array}$} & \multicolumn{4}{|c|}{ Outcome } & \multirow[b]{3}{*}{$\chi^{2}$} & \multirow[b]{3}{*}{ p-value } \\
\hline & \multicolumn{2}{|c|}{ Favorable } & \multicolumn{2}{|c|}{ Unfavorable } & & \\
\hline & $\mathrm{N}$ & $\%$ & $\mathrm{~N}$ & $\%$ & & \\
\hline \multicolumn{7}{|l|}{ Sex } \\
\hline Male & 26 & 63.4 & 16 & 76.2 & 0.54 & 0.464 \\
\hline Female & 15 & 36.6 & 5 & 23.8 & & \\
\hline \multicolumn{7}{|l|}{ Sexual risk behavior } \\
\hline Heterosexual & 26 & 63.4 & 11 & 52.4 & 0.03 & 0.861 \\
\hline MSM & 15 & 36.6 & 10 & 47.6 & & \\
\hline \multicolumn{7}{|l|}{ Intravenous drug user } \\
\hline Yes & 2 & 4.9 & 0 & 0 & 0.07 & 0.544 \\
\hline No & 39 & 95.1 & 21 & 100 & & \\
\hline \multicolumn{7}{|l|}{ Subtype } \\
\hline B & 30 & 73.1 & 17 & 80.9 & 0.07 & 0.792 \\
\hline $\mathrm{F}$ & 11 & 26.9 & 4 & 19.1 & & \\
\hline \multicolumn{7}{|l|}{ Pre-treatment viral load ${ }^{a}$ (copies/ml) } \\
\hline$<100,000$ & 12 & 36.3 & 4 & 25 & 0.22 & 0.637 \\
\hline$>100,000$ & 21 & 63.7 & 12 & 75 & & \\
\hline \multicolumn{7}{|l|}{ Scheme of treatment } \\
\hline 2 NRTI + NNRTI & 31 & 75.6 & 11 & 52.4 & 2.45 & 0.117 \\
\hline 2 NRTI + PI & 10 & 24.4 & 10 & 47.6 & & \\
\hline \multicolumn{7}{|l|}{ Basal CD $4{ }^{b}\left(\right.$ cells $\left./ \mathrm{mm}^{3}\right)$} \\
\hline$<100$ & 16 & 45.7 & 9 & 50 & 0.08 & 0.776 \\
\hline$\geq 100$ & 19 & 54.3 & 9 & 50 & & \\
\hline Mean basal CD $4 \pm \mathrm{SD}\left(\right.$ cells $\left./ \mathrm{mm}^{3}\right)$ & $142.1 \pm 113.9$ & - & $133.2 \pm 109.1$ & - & 0.071 & 0.790 \\
\hline Final CD4 + SD (cells $\left./ \mathrm{mm}^{3}\right)$ & $454.4 \pm 256.8$ & - & $377.1 \pm 151.7$ & - & 1.100 & 0.299 \\
\hline Duration of follow-up (months) & $22.2 \pm 9.4$ & - & $18.1 \pm 10.3$ & - & 2.395 & 0.126 \\
\hline
\end{tabular}

$a$ : 13 patients without basal viral load available; $b$ : 9 patients without basal CD4 values available; MSM: men-who-have-sex-with-men; NRTI: nucleoside reverse transcriptase inhibitor; NNRTI: non-nucleoside reverse transcriptase inhibitor; PI: protease inhibitor. 
ferent times, of a small number of viral strains into the Brazilian population, subtype B having been introduced in the early 1970s and, more recently, subtype F in the early 1980 s. This might have resulted in a lower prevalence of this subtype and a possible association between infection of female sex and heterosexuals, target groups infected later in the Brazilian epidemic (Brito et al. 2005, Bello et al. 2006).

It is already known that major resistance mutations are not common in non-B subtypes from drug-naïve patients, although minor mutations are frequent (Apetrei 2004, Kantor et al. 2005). Some of these polymorphisms are consensus sequences in certain subtypes, and several act as secondary resistance mutations in subtype B (Tanuri et al. 1999, Kantor et al. 2005). Some of the secondary protease mutations have been associated with reduced susceptibility to protease inhibitors in vitro and may also modulate viral fitness and influence the genetic barrier, facilitating the emergence of primary resistance mutations (Accetturi et al. 2000, Frater et al. 2001, Geretti 2006). However, a recent study using a phenotypic resistance assay did not show any association between the occurrence of the polymorphisms in non-B subtypes and the occurrence of resistance to antiretrovirals: the authors analysed 58 plasma-samples from drug-naïve patients with non-B subtypes and showed that two of them had reduced susceptibility to PI in the phenotypic resistance assay and also had mutations in codons K20I, M36I, L63P, and V82I. Curiously they demonstrated that several other viruses displayed the same constellation of mutations but did not show any reduction in susceptibility, suggesting that these polymorphisms per se do not affect the susceptibility of non-B subtypes to PI (Holquin et al. 2006). The present study did not show differences in the frequency of mutations between the two subtypes, but detected mutations related to PI which were significantly more frequent in subtype $\mathrm{B}$, such as the mutations in the codons 63,77 , and 71 , whereas others predominated in subtype $\mathrm{F}$, such as the mutations in the codons 36 and 20. This difference did not result in a worse treatment outcome in the patients with the subtypes B or F in the present study, so it does not seem to be clinically relevant. One must however stress that the small number of patients who received PI in the two subtypes certainly restricted the analysis of the differences in outcome in this antiretroviral group.

The present study is in accordance with other studies (Frater et al. 2002, Atlas et al. 2005, Geretti 2006), particularly a recent French cohort which included 416 patients starting first-line HAART with PI or NNRTI. Virological responses over 12 and 24 months were similar in the 317 patients with subtype B compared to 99 patients with the non-B subtypes (Bockect et al. 2005). On the contrary, a Brazilian study which compared the outcomes of treatment in patients with subtypes B and F showed that the treatment produced worse results in the patients with subtype $\mathrm{F}$ after 48 weeks of therapy (Acceturi et al. 2000). It should be borne in mind that the present study followed up patients for up to 80 weeks and did not detect any such differences. The proportion of patients that achieved an undetectable viral load at the end of the period was similar in the two subtypes. The average CD4 count did not show any significant differences in the two groups, either. No association could be found between treatment outcome and subtypes B or F of HIV-1. Finally, the higher number of deaths in the subtype B group, although not significantly different from the subtype $\mathrm{F}$ group, reinforces the conclusion that the F subtype of HIV-1 no less susceptible to HAART. However, evaluation of a greater number of individuals for each subtype are required to demonstrate this conclusively.

In conclusion, the results of this study, in spite of pointing to possible epidemiological and genetic differences among subtypes B and F of HIV-1, suggest that the use of HAART, despite having been developed and tested in countries where subtype B predominates, is equally effective against subtype $\mathrm{F}$.

\section{REFERENCES}

Accetturi CA, Pardini R, Novaes Pinto GH, Turcato G Jr, Lewi DS, Diaz RS 2000. Effects of CCR5 genetic polymorphism and HIV-1 subtype in antiretroviral response in Brazilian HIV-1-infected patients. J Acquir Immune Defic Syndr 24: 399-400.

Apetrei C, Marx PA, Smith SM 2004. The evolution of HIV and its consequences. Infect Dis Clin N Am 18: 369-394.

Atlas A, Granath F, Lindstrom A, Lidman K, Lindback S, Alaeus A 2005. Impact of HIV type 1 genetic subtype on the outcome of antiretroviral therapy. AIDS Res Hum Retroviruses 21: 221-227.

Avilla MM, Pando MA, Carrion G, Salomon H, Carrillo MG, Sanchez J, Maulen S, Hierholzer J, Marinello M, Negrete M, Russel KL, Carr JK 2002. Two HIV-1 epidemics in Argentina: different genetic subtypes associated with different risk groups. J Acquir Immune Defic Syndr 29: 422-426.

Barreto CC, Nishyia A, Araujo LV, Ferreira JE, Bush MP, Sabino EC 2006. Trends in antiretroviral drug resistance and clade distributions among HIV-1 infected blood donors in São Paulo, Brazil. J Acquir Immune Defic Syndr 41: 338-341.

Bello G, Guimarães ML, Morgado MG 2006. Evolutionary history of HIV-1 subtype B and F infection in Brazil. AIDS 20: 763-768.

Bocket L, Cheret A, Deuffic-Burban S, Choisy P, Gerard Y, de la Tribonniere X, Viget N, Ajana F, Goffard A, Barin F, Mouton Y, Yazdanpanah Y 2005. Impact of human immunodeficiency virus type 1 subtype on first-line antiretroviral therapy effectiveness. Antivir Ther 10: 247-254.

Brazilian Ministry of Health 2002. Consensus for the treatment of adults and adolescents with HIV infection. National Program of STD/AIDS, Brasília, 120 pp.

Brazilian Ministry of Health 2006. Boletim epidemiológico AIDS/ DST, ano III, no. 1, 1 $1^{\mathrm{a}}$ - 26 $6^{\mathrm{a}}$ Semana Epidemiológica, janeiro -junho.

Brindeiro R, Diaz RS, Sabino EC, Morgado MG, Pires IL, Brigido L, Dantas MC, Barreira D, Teixeira PR, Tanuri A and the Brazilian Network for Drug Resistence Surveillance 2003. Brazilian Network for HIV Drug Resistance Surveillance (HIV-BResNet): a survey of chronically infected individuals. AIDS 17: 1063-1069.

Brito AM, Castilho EA, Szwarchwald CL 2005. Regional patterns of the temporal evolution of the AIDS epidemic in Bra- 
zil following the introduction of antiretroviral therapy. Braz J Infect Dis 9: 9-19.

Cerqueira DM, Amorim RM, Silva RR, Camara GN, Brigido MM, Martins CR 2004. Antiretroviral resistance and genetic diversity of human immunodeficiency vírus type 1 isolates from the Federal District, Central Brazil. Mem Inst Oswaldo Cruz 99: 877-882.

Couto-Fernandes JC, Silva-de-Jesus C, Veloso VG, Rachid M, Gracie RSG, Chequer-Fernandez SL, Oliveira SM, ArakakiSanchez D, Chequer PJN, Morgado MG 2005. Human immunodeficiency vírus type 1 genotyping in Rio de Janeiro, Brazil: assessing subtype and drug-resistance associated mutaions in HIV-1 infected individuals failing highly active antiretroviral therapy. Mem Inst Oswaldo Cruz 100: 73-78.

D’Aquilla RT, Shapiro JM, Brun-Vézinet F, Clotet B, Conway B, Demeter LM, Grant RM, Johnson VA, Kuritzes DR, Loveday C, Shafer RW, Richmann DD, International AIDS SocietyUSA 2002. Drug resistance mutations in HIV-1. Top HIV Med 10: 21-25.

Essex M, Soto-Rodrigues LE, Renjifo E, Wang WK, Lee TH 1997. Genetic variation within human immunodeficiency viruses generates rapid changes in tropism, virulence, and transmission. Leukemia 11: S93-S94.

Fleury HJ, Toni TA, Lan NTH, Hung PV, Deshpande A, Recordon-Pinson P, Boucher S, Lazaro E, Jauvin V, Lavignolle-Aurillac V, Lebel-binay S, Cheret A, Masquelier B 2005. Susceptibility to ARV's of CRF01_AE, CRF02_AG and subtype $C$ viruses from naïve patients: comparative genotypical and phenotypical data. Antivir Ther 10: S148.

Frater J 2002. The impact of HIV-1 subtype on the clinical response on HAART. J HIV Ther 7: 92-96.

Frater AJ, Beardall A, Ariyoshi K, Churchill D, Galpin S, Clark JR 2001. Impact of baseline polymorphisms in RT and protease on outcome of highly active antiretroviral therapy in HIV-1 infected African patients. AIDS 15: 1493-1502.

Frater AJ, Dunn DT, Beardall AJ, Ariyoshi K, Clarke JR, McClure MO 2002. Comparative response of African HIV-1 infected individuals to highly active antiretroviral therapy. AIDS 16: 1139-1146.

Geretti AM 2006. HIV-1 subtypes: epidemiology and significance for HIV management. Curr Opin Infect Dis 19: 1-7.

Holquin A, Ramirez de Arellano E, Rivas P, Soriano V 2006. Efficacy of antiretroviral therapy in individuals infected with HIV-1 non-B subtypes. AIDS Rev 8: 98-107.

Kantor R, Katzenstein DA, Efron B et al. 2005. Impact of HIV1 subtype and antiretroviral therapy on protease and reverse transcriptase genotype: results of a global collaboration. Plos Medicine 2: 325-336.

Kuiken C, Korber B, Shafer RW 2003. HIV sequence databases. AIDS Rev 5: 52-61.
Masciotra S, Livellara B, Belloso W, Clara L, Tanuri A, Ramos AC, Baggs J, Lal R, Pieniazek D 2000. Evidence of a high frequency of HIV-1 subtype $\mathrm{F}$ infections in heterosexual population in Buenos Aires, Argentina. AIDS Res Hum Retroviruses 16: 1007-1014.

Montano SM, Sanchez JL, Laguna-Torres A et al. 2005. Prevalences, genotypes, and risk factors for HIV transmission in South America. J Acquir Immune Defic Syndr 40: 57-64.

Pinto ME, Struchiner CJ 2006. HIV-1 diversity: a tool for studying the pandemic. Reports in Public Health 22: 473-484.

Pires IL, Soares MA, Speranza FA, Ishii SK, Vieira MCG, Gouvêa MIFS, Guimarães MAAM, Oliveira FE, Magnanini MMF, Brindeiro RM, Tanuri A 2004. Prevalence of human immunodeficiency virus drug resistance mutations and subtypes in drug-naïve, infected individuals in the Army Health Service of Rio de Janeiro, Brazil. J Clin Microbiol 42: 426-430.

Rios M, Fernandez J, Jaramillo P, Paredes V, Sanchez JL, Laguna-Torres VA, Carr JK, Ramirez E 2005. Molecular epidemiology of HIV type 1 in Chile: differential geographic and transmission route distribution of $\mathrm{B}$ and $\mathrm{F}$ subtypes. AIDS Res Hum Retroviruses 21: 835-840.

Rodrigues R, Vazquez CMP, Colares JK, Custodio RM, Bonasser Filho F, Souza LR, Gianna MC, Marques CCA, Brigido LFM 2005. Antiretroviral resistance mutations in human immunodeficiency vírus type 1 infected patients enrolled in genotype testing at the Central Public Health Laboratory, São Paulo, Brazil: preliminary results. Mem Inst Oswaldo Cruz 100: 97-102.

Soares EAJM, Santos RP, Pellegrini JA, Sprinz E, Tanuri A, Soares M 2003. Epidemiologic and molecular characterization of human immunodeficiency virus type 1 in Southern Brazil. J Acquir Immune Defic Syndr 34: 520-526.

Solis M, Wilkinson P, Romieu R, Hernandez E, Wainberg MA, Hiscott J 2006. Gene expression profiling of the host response to HIV-1 B, C or A/E infection in monocyte-derived dendritic cells. Virology 352: 86-99.

Soto-Ramirez LE, Renjifo B, McLane MF, Marlink R, O'Hara C, Sutthent R 1996. HIV-1 Langerhans' cell tropism associated with heterosexual transmission of HIV. Science 271: 1291-1293.

Stanford University HIV drug resistance database. Available at http://hivdb.stanford.edu/; cited 18 november 2006.

Tanuri A, Vicente AC, Otsuki K, Ferreira OC, Schechter M, Janini LM, Pieniazek D, Rayfield MA 1999. Genetic variation and susceptibilities to protease inhibitors among subtypes $\mathrm{B}$ and $\mathrm{F}$ isolates in Brazil. Antimicrob Agents Chemother 43: 253-258.

Thompson MM, Pérez-Álvarez L, Nájera R 2002. Molecular epidemiology of HIV-1 genetic forms and its significance for vaccine development and therapy. Lancet Infect Dis 2: 461-471. 
